\title{
Dielectric interface-dependent spatial charge distribution in ambipolar polymer semiconductors embedded in dual-gate field-effect transistors
}

\section{Citation for published version (APA):}

Lee, J., Roelofs, W. S. C., Janssen, R. A. J., \& Gelinck, G. H. (2016). Dielectric interface-dependent spatial charge distribution in ambipolar polymer semiconductors embedded in dual-gate field-effect transistors. Applied Physics Letters, 109(4), [043301]. https://doi.org/10.1063/1.4960096

DOI:

$10.1063 / 1.4960096$

Document status and date:

Published: 25/07/2016

\section{Document Version:}

Publisher's PDF, also known as Version of Record (includes final page, issue and volume numbers)

\section{Please check the document version of this publication:}

- A submitted manuscript is the version of the article upon submission and before peer-review. There can be important differences between the submitted version and the official published version of record. People interested in the research are advised to contact the author for the final version of the publication, or visit the DOI to the publisher's website.

- The final author version and the galley proof are versions of the publication after peer review.

- The final published version features the final layout of the paper including the volume, issue and page numbers.

Link to publication

\footnotetext{
General rights

- You may freely distribute the URL identifying the publication in the public portal. follow below link for the End User Agreement:

www.tue.nl/taverne

\section{Take down policy}

If you believe that this document breaches copyright please contact us at:

openaccess@tue.nl

providing details and we will investigate your claim.
}

Copyright and moral rights for the publications made accessible in the public portal are retained by the authors and/or other copyright owners and it is a condition of accessing publications that users recognise and abide by the legal requirements associated with these rights.

- Users may download and print one copy of any publication from the public portal for the purpose of private study or research.

- You may not further distribute the material or use it for any profit-making activity or commercial gain

If the publication is distributed under the terms of Article 25fa of the Dutch Copyright Act, indicated by the "Taverne" license above, please 
Dielectric interface-dependent spatial charge distribution in ambipolar polymer semiconductors embedded in dual-gate field-effect transistors

Jiyoul Lee' , W. S. Christian Roelofs, Rene A. J. Janssen, and Gerwin H. Gelinck

Citation: Appl. Phys. Lett. 109, 043301 (2016); doi: 10.1063/1.4960096

View online: http://dx.doi.org/10.1063/1.4960096

View Table of Contents: http://aip.scitation.org/toc/apl/109/4

Published by the American Institute of Physics 


\title{
Dielectric interface-dependent spatial charge distribution in ambipolar polymer semiconductors embedded in dual-gate field-effect transistors
}

\author{
Jiyoul Lee, ${ }^{1,2, a)}$ W. S. Christian Roelofs, ${ }^{3}$ Rene A. J. Janssen, ${ }^{3}$ and Gerwin H. Gelinck ${ }^{2,3}$ \\ ${ }^{1}$ Department of Graphic Arts Information Engineering, Pukyong National University, Sinseonro 365, Nam-gu, \\ Busan, 48547, South Korea \\ ${ }^{2}$ Holst Centre/TNO, High Tech Campus 31, 5656 AE Eindhoven, The Netherlands \\ ${ }^{3}$ Department of Applied Physics, Eindhoven University of Technology, P. O. Box 513, 5600 MB Eindhoven, \\ The Netherlands
}

(Received 21 March 2016; accepted 17 July 2016; published online 28 July 2016)

\begin{abstract}
The spatial charge distribution in diketopyrrolopyrrole-containing ambipolar polymeric semiconductors embedded in dual-gate field-effect transistors (DGFETs) was investigated. The DGFETs have identical active channel layers but two different channel/gate interfaces, with a CYTOP ${ }^{\mathrm{TM}}$ organic dielectric layer for the top-gate and an octadecyltrichlorosilane (ODTS) self-assembled monolayer-treated inorganic $\mathrm{SiO}_{2}$ dielectric for the bottom-gate, respectively. Temperaturedependent transfer measurements of the DGFETs were conducted to examine the charge transport at each interface. By fitting the temperature-dependent measurement results to the modified Vissenberg-Matters model, it can be inferred that the top-channel interfacing with the fluorinated organic dielectric layers has confined charge transport to two-dimensions, whereas the bottomchannel interfacing with the ODTS-treated $\mathrm{SiO}_{2}$ dielectric layers has three-dimensional charge transport. Published by AIP Publishing. [http://dx.doi.org/10.1063/1.4960096]
\end{abstract}

Solution-processable organic ambipolar semiconductors, wherein both $p$ - and $n$-type charge transport can occur, are attracting significant research interest because of their advantages that potentially allow easy fabrication of light-emitting transistors or inverting logic circuits. ${ }^{1-5}$ A promising class of organic materials for such ambipolar characteristics is based on diketopyrrolopyrrole (DPP)-containing copolymers that consist of DPP-acceptor and a large variety of donor blocks and exhibit a high mobility up to $>10 \mathrm{~cm}^{2} / \mathrm{V} \mathrm{s}$, as has been reported by several groups. ${ }^{6}$ An improved understanding of the physical properties of ambipolar charge transport is required in order to expedite progress in the performance of DPP-based organic electronic applications. For this purpose, Kronemeijer et al. recently reported the confined twodimensional charge-transport behavior in top-gated fieldeffect transistors, wherein organic gate dielectrics were located on the top of the semiconducting layers, and several polymeric semiconductors, including DPP-based polymers, were used as active channel materials. ${ }^{7}$ However, their results contradicted those reported by Brondijk et al., who observed that $\mathrm{SiO}_{2}$ bottom-gated field-effect transistors with polymer semiconductor films are well-described by the three-dimensional charge transport model. ${ }^{7,8}$

In order to address these conflicting observations, we study the charge transport properties of DPP-based ambipolar semiconducting polymers embedded in dual-gate field-effect transistors (DGFETs) comprising two separate dielectric/ semiconductor interfaces in a single transistor. ${ }^{9,10}$ In fact, the DGFET structure is the best platform for studying the effects of different dielectrics upon device performance with minimal influence from external parameters, such as sample-to-sample variation, because the devices share an identical active

\footnotetext{
${ }^{\text {a) }}$ Author to whom correspondence should be addressed. Electronic mail: jiyoul_lee@pknu.ac.kr
}

semiconductor layer. ${ }^{9,10}$ In the present work, we perform temperature-dependent transfer-curve measurements on the DGFETs in the range of $120-260 \mathrm{~K}$. Based on these measurements, we analyze the spatial charge-transporting behavior of holes in the active DPP-based semiconducting layer interfacing with the organic top-gate (TG) and $\mathrm{SiO}_{2}$ bottomgate (BG) dielectric layers. We also correlate key chargetransport parameters with the dielectric layers that we have studied.

Figure 1(a) shows a schematic of the DGFETs and the chemical structure of poly[(diketopyrrolopyrrole)-alt- $\left(2,2^{\prime}-\right.$ (1,4-phenylene)bisthiophene)] (PDPPTPT) used as an active channel layer. ${ }^{11,12}$ Fabrication of the DGFETs starts with a heavily doped $\left(n^{++}\right)$Si substrate that also serves as a bottomgate electrode. On the top of the Si substrate, a $200 \mathrm{~nm}$-thick silicon dioxide $\left(\mathrm{SiO}_{2}, \varepsilon_{r}=3.9\right)$ dielectric layer with a capacitance of $17 \mathrm{nF} / \mathrm{cm}^{2}$ is thermally grown. For the source and drain (S/D) electrodes, a $30 \mathrm{~nm}$-thick gold $(\mathrm{Au})$ layer with a

(a)

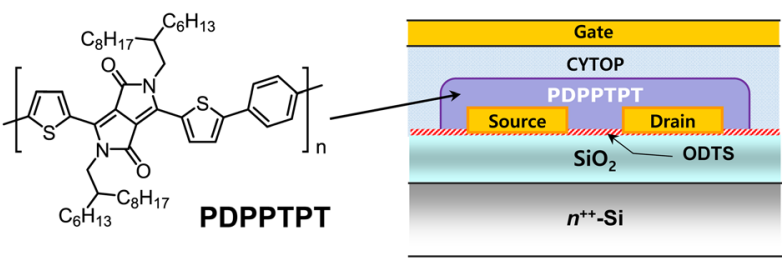

(b)

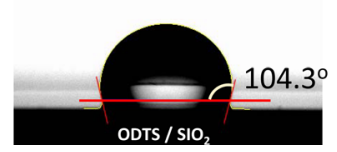

(c)

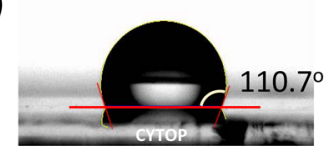

FIG. 1. (a) Schematics of the transistor and the chemical structure of the PDPPTPT used in this study. Deionized water contact angles with (b) ODTS-treated $\mathrm{SiO}_{2}$ and (c) CYTOP surfaces. 
$5 \mathrm{~nm}$-thick titanium (Ti) adhesion layer is thermally evaporated onto the $\mathrm{SiO}_{2}$ surfaces and photolithographically patterned. The width and length of the comb-shaped interdigitating S/D electrodes are $5 \mathrm{~mm}$ and $10 \mu \mathrm{m}$, respectively.

To passivate hydroxyl groups on the $\mathrm{SiO}_{2}$ surfaces that are known to act as electron-trap sites, the substrate is immersed in a $10 \mathrm{mmol}$ octadecyltrichlorosilane (ODTS)-concentrated $n$-hexane solution for $30 \mathrm{~min}$ after UV-ozone cleaning. The substrate is then rinsed with ethanol and baked for $30 \mathrm{~min}$ at $120^{\circ} \mathrm{C}$ in ambient air to accelerate the surface reaction. The ODTS monolayer on top of the $\mathrm{SiO}_{2}$ surfaces has a contact angle of $>104^{\circ}$, as shown in Figure 1(b). Next, the PDPPTPT (synthesized according to a previously reported procedure $^{11}$ ) is spin-coated from a $10 \mathrm{mg} / \mathrm{ml}$ solution in hot chloroform, and the semiconducting polymer films are annealed at $200{ }^{\circ} \mathrm{C}$ for $30 \mathrm{~min}$ in the glove box with an atmosphere $<0.1 \mathrm{ppm}$ oxygen and water. The PDPPTPT-based polymer film's thickness, as measured by atomic force microscopy, is $\sim 50 \mathrm{~nm}$. Subsequently, a fluorinated polymer, CYTOP $^{\mathrm{TM}}\left(\varepsilon_{r}=2.1\right.$, purchased from Asahi Glass Co.) is spincoated and annealed at $150{ }^{\circ} \mathrm{C}$ in vacuum for $24 \mathrm{~h}$ to be used as a top-gate dielectric layer. The thickness of the CYTOP dielectric layer is $\sim 750 \mathrm{~nm}$, resulting in a capacitance of $\sim 2.4$ $\mathrm{nF} / \mathrm{cm}^{2}$, and the surface of the CYTOP layer has a contact angle of $>110^{\circ}$ (Figure 1(c)), which indicates the highly hydrophobic state of the CYTOP surface. Finally, the top-gate electrode is applied by thermally evaporating $\mathrm{Au}(50 \mathrm{~nm})$ through a shadow mask. The DGFETs were characterized using a Keithley 4200-SCS semiconductor analyzer connected to a Desert Cryogenics vacuum probe station with a chamber pressure below $10^{-3}$ Torr at room temperature (RT).

The electrical characteristics of the DGFETs are shown in Figure 2. For both the TG and BG channels, the typical transfer and output characteristics of ambipolar operating behavior are observed. In particular, Figures 2(a) and 2(b) show the transfer characteristics of both channels for positive and negative drain biases $\left(V_{D}\right)$, which have symmetric $\mathrm{V}$-shaped curves indicating the transition from $n$ - to $p$-type and vice versa. A large ON/OFF ratio of $>10^{4}$ at $\left|V_{D}\right|=20 \mathrm{~V}$ for both channels is found in their transfer curves. From the slope of negative $V_{G}$ vs. $\sqrt{\left|I_{D}\right|}$, the hole-mobility of the saturation region is calculated to be $\sim 0.39$ and $\sim 0.06 \mathrm{~cm}^{2} / \mathrm{V}$ s for the TG and BG channels, respectively, and the electron mobilities extracted from the slope of positive $V_{G} v s . \sqrt{\left|I_{D}\right|}$ are $\sim 0.18$ and $\sim 0.06 \mathrm{~cm}^{2} / \mathrm{V}$ $\mathrm{s}$ for $\mathrm{TG}$ and $\mathrm{BG}$, respectively. For both hole and electron transport, the charge-carrier mobility in the TG channel is more than three times higher than that in BG channel, although the thermally grown $\mathrm{SiO}_{2} \mathrm{BG}$ dielectric has a higher capacitance value compared with the CYTOP TG dielectrics, resulting in a substantially larger field-induced charge density in the BG channel. The origin of the different charge carrier mobilities will be discussed later. Figures 2(c) and 2(d) show the output characteristics with proper saturation at high gate biases. However, particularly for the electron-accumulation mode, we also observe a super linear drain current increase at low gate biases $\left(\left|V_{G}\right| \leq 50 \mathrm{~V}\right) .{ }^{13}$ In this bias condition, the minority carriers (i.e., holes in the $n$-type mode and electrons in the $p$-type mode) flow dominantly as the drain also works as a source when the $\left|V_{G D}\right|$ is larger than $\left|V_{G S}\right|$.

In order to further examine the charge transport, temperature-dependent transfer-measurements were conducted on the PDPPTPT-based DGFETs in the range of $120-260 \mathrm{~K}$. Figures 3(a) and 3(b) show the measured temperaturedependent transfer curves at a $V_{D}$ of $-40 \mathrm{~V}$ in the TG and BG channels, respectively. We note that the drain currents of the output curves shown in Figures 2(c) and 2(d) display a nonlinearity at low drain-bias conditions (i.e., in the linear regime) due to poor charge injection that is generally found in DPPcontaining polymer-based ambipolar transistors with single $\mathrm{Au}$ S/D contacts. ${ }^{5}$ Therefore, we measure the drain currents of the DGFETs in the saturation region of $V_{D}=-40 \mathrm{~V}$ to minimize potential errors. As expected in thermally activated transport, the charge-carrier mobilities of both electrons and holes increase with increasing temperature. Figures 3(c) and 3(d) show plots of the charge-carrier mobility versus inverse temperature for both hole- and electron-accumulation modes with
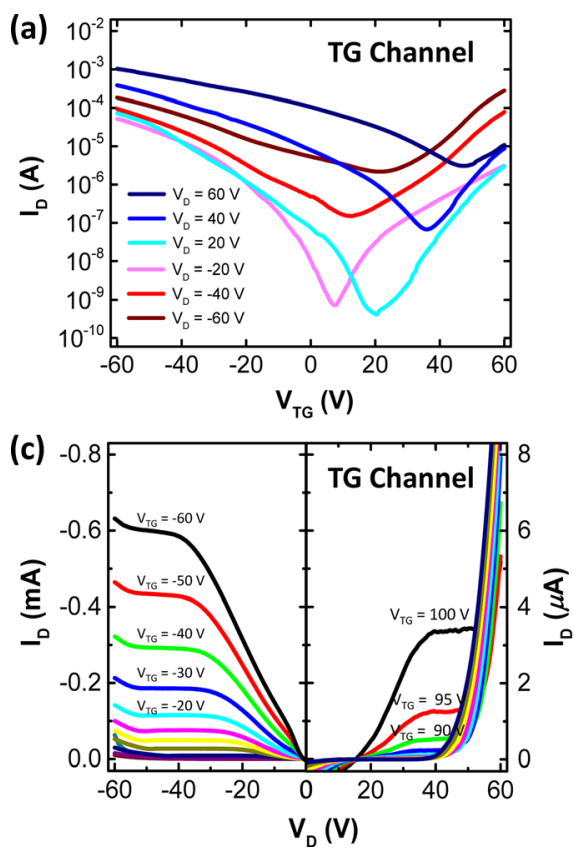
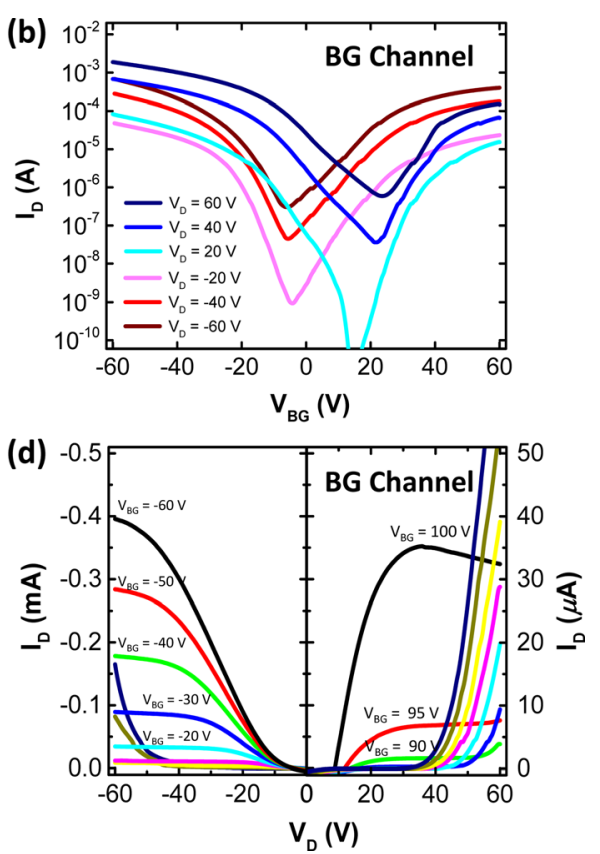

FIG. 2. Transfer characteristics of (a) the TG channel and (b) the BG channel at different source-drain bias conditions. Output characteristics of (c) the TG channel and (d) the BG channel. 

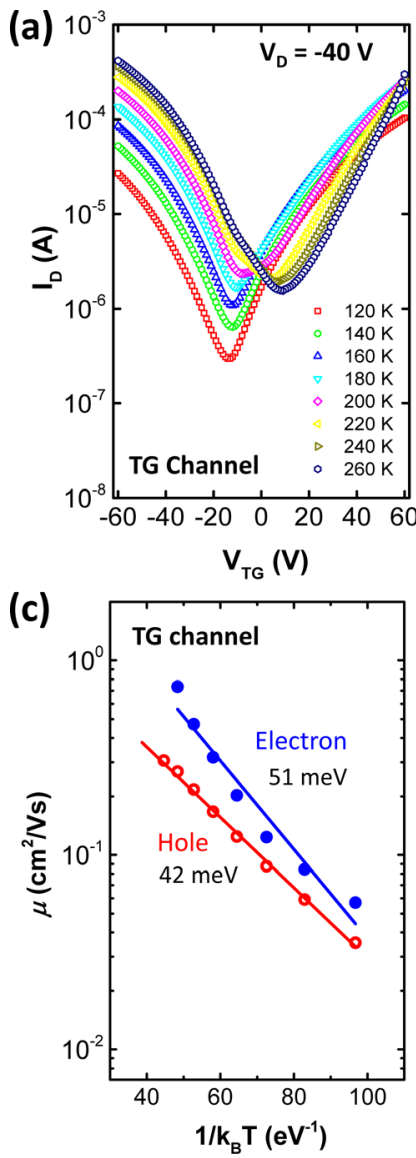

density profile in the accumulation layer that decreases quadratically with distance from the dielectric. ${ }^{15}$ For the analysis of self-assembled monolayer transistors, however, Brondijk et al. revised the analytical model with a two-dimensional carrier-distribution profile in the accumulation layer of the transistor, in which the charge density is constant up to a certain limited thickness from the dielectric. ${ }^{7,8}$ Recently, Kronemeijer et al. modified the Vissenberg-Matters model again to be appropriate to the charge transport in the saturation regime of the transistors as follows: ${ }^{7}$

$$
\begin{aligned}
& I_{D}^{2 D}=A \frac{W}{L} d_{s c}^{1-\left(T_{0} / T\right)}\left(\frac{C_{i}}{e}\right)^{T_{0} / T} \frac{T}{T_{0}+T}\left(V_{G}-V_{t}\right)^{\left(T_{0} / T\right)+1} \\
& I_{D}^{3 D}=\frac{A}{e} \frac{W}{L}\left(\frac{1}{2 K_{b} T_{0} \varepsilon_{0} \varepsilon_{r}}\right)^{\left(T_{0} / T\right)-1} C_{i}^{2 T_{0} / T-1} \\
& \times \frac{T}{2 T_{0}} \frac{T}{2 T_{0}+T}\left(V_{G}-V_{t}\right)^{2 T_{0} / T}
\end{aligned}
$$

with

$$
A=\sigma_{0}\left(\frac{\left(\frac{T_{0}}{T}\right)^{4} \sin \left(\pi \frac{T}{T_{0}}\right)}{(2 \alpha)^{3} B_{c}}\right)^{T_{0} / T}
$$

where $T_{0}$ is the characteristic width of the exponential density of states, $\alpha^{-1}$ is the wave-function overlap localization length, $\sigma_{0}$ is a conductivity prefactor, and $B_{c}$ is the critical number for the onset of percolation. The parameter $d_{s c}$ is the thickness of the confined two-dimensional charge sheet. More importantly, the above complicated equations are reduced to an approximate power-law dependence of the source-drain current on the gate voltage without the Taylor expansion. Consequently, both the two- and three-dimensional models lead to direct power laws, i.e., $I_{D} \propto a\left(V_{G}-V_{t}\right)^{\gamma}$, where $a$ is a fitting constant that comprises several physical parameters (e.g., $A$ in Equation (3) and device geometry factors) and the exponent $\gamma$ is a function of temperature (e.g., $\gamma_{2 \mathrm{D}}=\left(T_{0} / T\right)+1$ and $\gamma_{3 \mathrm{D}}$ $=2 T_{0} / T$ in the saturation regime), which carries information about the spatial charge-transport behavior. ${ }^{7,8}$

Figures 4(a) and 4(b) show plots of the temperaturedependent transfer curves on a double logarithmic scale for the TG and BG channels, respectively. We note that there are instability of the turn-on voltages and drain-gate leakage currents that are slightly greater than the source-drain currents at the elevated temperature for the electron-accumulation mode. ${ }^{19}$ For this reason, only hole-transport is analyzed using the modified Vissenberg-Matters model. Solid lines are obtained for all temperatures by fitting the measured data to the reduced power-law dependence of the source-drain current as a function of the gate-overdrive voltage $\left(V_{\mathrm{G}}-V_{\mathrm{t}}\right)$, where the $V_{t}$ values were $-1.5 \mathrm{~V}$ and $-11 \mathrm{~V}$ for the TG and BG channels, respectively. The $\gamma$ value is also extracted from the measured transfer curve for each temperature and is then plotted against inverse temperature $(1 / T) .^{7,8,15}$ Figure 4(c) shows the $\gamma$ versus $1 / T$ plots constructed for both the TG and BG channels. The extrapolated line of the TG channel crosses the exponential axis at a value of 1 , indicating that the two-dimensional charge-carrier profile is presented in the top-channel, whereas the extrapolated line of 

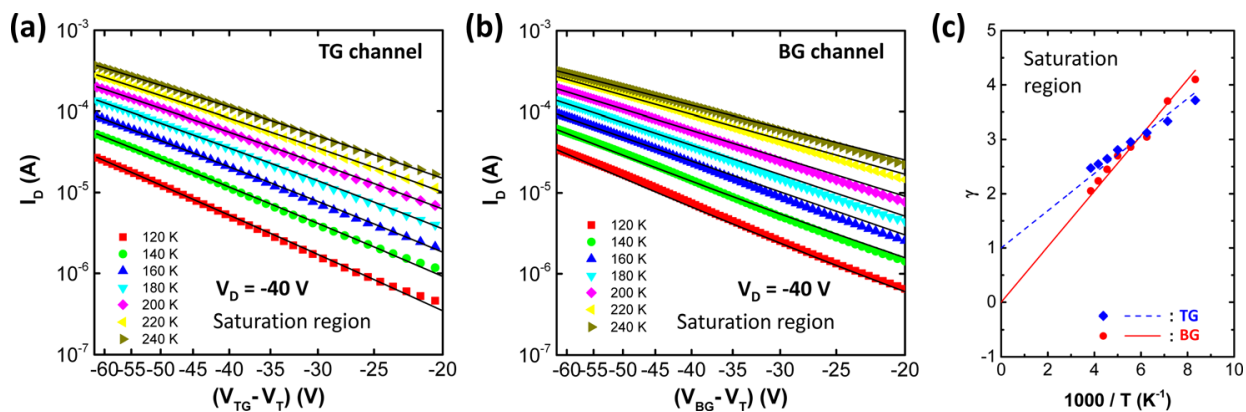

FIG. 4. Replotted transfer characteristics of (a) the TG channel and (b) the BG channel on a double-logarithmic scale. Black solid lines are fits to extract the parameter, $\gamma$, for each temperature. (c) Extracted values of $\gamma$ for the TG and BG channels plotted against inverse temperature. The extrapolated dashed linear fit yields the intersection with the exponential axis.

TABLE I. Summary of key charge transport parameters: room-temperature mobility $\mu_{\mathrm{RT}}$, activation energy $E_{a}$, width of the density of localized states $k_{B} T_{0}$, and information about the dielectric layers.

\begin{tabular}{|c|c|c|c|c|c|c|}
\hline \multirow[b]{2}{*}{ Channel } & \multirow[b]{2}{*}{ Dielectric $\left(\varepsilon_{r}\right)$} & \multicolumn{2}{|c|}{ Electron } & \multicolumn{3}{|c|}{ Hole } \\
\hline & & $\mu_{R T}\left(\mathrm{~cm}^{2} / \mathrm{V} \mathrm{s}\right)$ & $E_{a}(\mathrm{meV})$ & $\mu_{R T}\left(\mathrm{~cm}^{2} / \mathrm{V} \mathrm{s}\right)$ & $E_{a}(\mathrm{meV})$ & $k_{B} T_{0}(\mathrm{meV})$ \\
\hline Top & CYTOP (2.1) & 0.18 & 51 & 0.39 & 42 & 29.5 \\
\hline Bottom & $\mathrm{SiO}_{2}(3.9)$ & 0.06 & 49 & 0.06 & 26 & 44.1 \\
\hline
\end{tabular}

the BG channel has an exponential axis intercept of $\gamma=0$, which means that the three-dimensional profile is proper for describing the charge carrier distributions in the bottomchannel. ${ }^{7}$ A summary of key charge transport parameters and information about the dielectric layers is presented in Table I, where we use fluorinated organic layers with a relatively low dielectric constant for the TG-insulating materials and ODTStreated $\mathrm{SiO}_{2}$ dielectrics, which have dielectric constants that are almost two times higher than those of the organic layers used as BG dielectric layers. Given the fact that the surface of the ODTS-treated $\mathrm{SiO}_{2}$ is hydrophobic, as confirmed with the contact angle measurement (Figure 1(b)), we assume that the interfacial states of both channels have similar quality; thus, we infer that differences in the electrostatic interaction with the gate dielectric arise from the different dielectric constant values of the TG- and BG-dielectric layers. Therefore, the difference in the spatial charge distributions may originate from the different gate dielectric layers affecting the active channel, resulting in a substantial broadening of the density of the localized states (dipolar disorder) ${ }^{8,20,21}$ This interpretation is also supported by the values of $T_{0}$ (i.e., the characteristic width of the exponential density of states) extracted from the slopes of the linear fits in the $\gamma$ vs. 1/T plots. However, the higher charge-carrier mobility of the TG channel with higher thermal activation energy could not be explained. Compared with the ODTS-treated $\mathrm{SiO}_{2}$ dielectrics, the fluorinated organic CYTOP layer with a low dielectric constant induces a relatively small number of charge carriers in the TG channel under the same bias condition onto the BG dielectric layer. Although this small number of charges is insufficient to fill the adjacent trap sites and leads to a higher thermal activation energy, the narrow width of the density of the states resulting from the electrostatic interactions with the low- $k$ organic TG dielectrics allows an efficient hopping process of the induced charges; this results in the higher charge-carrier mobility of the TG channel $^{8,20-22}$

In summary, we have investigated the spatial charge transporting properties in a PDPPTPT-based ambipolar polymeric semiconductor embedded in a DGFET consisting of two separate dielectric/semiconductor interfaces in a single transistor. Temperature-dependent measurement results on the TG channels interfacing with the low-dielectric constant organic fluorinated insulating layer are compared with the results obtained from the BG channel contact with ODTS-treated $\mathrm{SiO}_{2}$ dielectrics. The modified Vissenberg-Matters model indicates that the top-channel has a two-dimensional charge-distribution profile, whereas the bottom-channel has a threedimensional charge distribution.

This work was supported by Holst Centre and the Basic Science Research Program through the National Research Foundation (NRF) funded by the Ministry of Science, ICT, and Future Planning of Korea (Code No. 2015R1C1A1A02037534). The authors wish to acknowledge the helpful comments of Dr. Auke J. Kronemeijer at Host Centre.

${ }^{1}$ E. J. Meijer, D. M. de Leeuw, S. Setayeshi, E. van Veenendaal, B.-H. Huisman, P. W. M. Blom, J. C. Hummelen, U. Scherf, and T. M. Klapwijk, Nat. Mater. 2, 678 (2003).

${ }^{2}$ J. Zaumseil, R. H. Friend, and H. Sirringhaus, Nat. Mater. 5, 69 (2006).

${ }^{3}$ J. Zaumseil, C. L. Donley, J.-S. Kim, R. H. Friend, and H. Sirringhaus, Adv. Mater. 18, 2708 (2006).

${ }^{4}$ W. S. C. Roelofs, S. G. J. Mathijssen, J. C. Bijleveld, D. Raiteri, T. C. T. Geuns, M. Kemerink, E. Cantatore, R. A. J. Janssen, and D. M. de Leeuw, Appl. Phys. Lett. 98, 203301 (2011).

${ }^{5}$ A. J. Kronemeijer, E. Gili, M. Shahid, J. Rivnay, A. Salleo, M. Heeney, and H. Sirringhaus, Adv. Mater. 24, 1558 (2012).

${ }^{6}$ C. B. Nielsen, M. Turbiez, and I. McCulloch, Adv. Mater. 25, 1859 (2013).

${ }^{7}$ A. J. Kronemeijer, V. Pecunia, D. Venkateshvaran, M. Nikolka, A. Sadhanala, J. Moriarty, M. Szumilo, and H. Sirringhaus, Adv. Mater. 26, 728 (2014).

${ }^{8}$ J. J. Brondijk, W. S. C. Roelofs, S. G. J. Mathijssen, A. Shehu, T. Cramer, F. Biscarini, P. W. M. Blom, and D. M. de Leeuw, Phys. Rev. Lett. 109, 056601 (2012).

${ }^{9}$ F. Maddalena, M. Spijkman, J. J. Brondijk, P. Fonteijn, F. Brouwer, J. C. Hummelen, D. M. de Leeuw, P. W. M. Blom, and B. de Boer, Org. Electron. 9, 839 (2008).

${ }^{10}$ A. K. Tripathi, E. C. P. Smits, M. Loth, J. E. Anthony, and G. H. Gelinck, Appl. Phys. Lett. 98, 202106 (2011). 
${ }^{11}$ J. C. Bijleveld, V. S. Gevaerts, D. D. Nuzzo, M. Turbiez, S. G. J. Mathijssen, D. M. de Leeuw, M. M. Wienk, and R. A. J. Janssen, Adv. Mater. 22, E242-E246 (2010).

${ }^{12}$ W. S. C. Roelofs, M.-J. Spijkman, S. G. J. Mathijssen, R. A. J. Janssen, D. M. de Leeuw, and M. Kemerink, Adv. Mater. 26, 4450 (2014).

${ }^{13}$ E. C. P. Smits, T. Anthopoulos, S. Setayesh, E. van Veenendaal, R. Coehoorn, P. W. M. Blom, B. de Boer, and D. M. de Leeuw, Phys. Rev. B 73, 205316 (2006).

${ }^{14}$ Z. Chen, M. Bird, V. Lemaur, G. Radtke, J. Cornil, M. Heeney, I. McCulloch, and H. Sirringhaus, Phys. Rev. B 84, 115211 (2011).

${ }^{15}$ M. C. J. M. Vissenberg and M. Matters, Phys. Rev. B 57, 12964 (1998).

${ }^{16}$ N. Tessler and Y. Roichman, Org. Electron. 6, 200 (2005).
${ }^{17}$ C.-H. Kim, Y. Bonnassieux, and G. Horowitz, IEEE Trans. Electron Devices 61, 278 (2014).

${ }^{18}$ S. D. Baranovskii, Phys. Status Solidi B 251, 487 (2014).

${ }^{19}$ J. Veres, S. D. Ogier, S. W. Leeming, D. C. Cupertino, and S. Mohialdin Khaffaf, Adv. Funct. Mater. 13, 199 (2003).

${ }^{20}$ See supplementary material at http://dx.doi.org/10.1063/1.4960096 for the VG versus ID and IG curves of the dual-gate field-effect transistors at each temperature, ranging from $120 \mathrm{~K}$ to $260 \mathrm{~K}$.

${ }^{21}$ T. Richards, M. Bird, and H. Sirringhaus, J. Chem. Phys. 128, 234905 (2008).

${ }^{22}$ J. Lee, B. Cho, J. W. Chung, and M. S. Kang, Appl. Phys. Lett. 103, 163302 (2013). 